\title{
ON THE PROGNOSIS OF CRETINISM
}

\author{
BY \\ DAVID LAWSON \\ From The Hospital for Sick Children, Great Ormond Street, London
}

(RECEIVED FOR PUBLCATION SEPTEMBER 15, 1954)

History of the Recognition of Sporadic Cretinism

Endemic cretinism, and its association with endemic goitre, or 'bronchocoele', have been known for many centuries, but sporadic cretinism occurring in non-endemic areas was first clearly described as a separate entity by Fagge in 1871 .

Absence of the thyroid gland was first observed by Curling (1850) at necropsies upon two typical cretins. He commented that the association of the features of cretinism both with enlargement of the gland, as in endemic cretinism, and with its total absence, as in these two cases, could hardly be a coincidence. Fagge (1871) in his original description of sporadic cretinism carried this line of argument further in putting forward the speculative but correct hypothesis that the hypertrophy in endemic cretinism represented an unsuccessful attempt to 'protect against the more severe defects of the endemic influence': if this attempt were unsuccessful the end-results might be the same as those of a congenital defect. One of Fagge's four cases had been normal until an attack of measles at the age of 8, after which signs of hypothyroidism developed. This observation led him to predict the symptomatology which might result were the disease to supervene in adult life. Three years later his predictions were fulfilled in Gull's (1874) description of the first two cases of what was later called 'myxoedema', in a paper entitled 'On a Cretinoid State Supervening in Adult Life in Women'. In 1878 Ord described a necropsy on such a case, in which fibrotic changes were present in the thyroid gland. He thought that the intercellular substance deposited in the subcutaneous tissues was a mucin, and that its accumulation was due to the failure of the thyroid gland to perform its postulated normal function of excreting mucin. He suggested the term 'myxoedema'. This name has clung, although both the suppositions on which it was based-on the nature of the intercellular material and on the function of the thyroid-were very soon proved false.

Kocher (1883) reviewed a series of 101 thyroidectomies with an operative mortality of just over
$10 \%$, and good short-term results in the other $90 \%$. While carrying out these operations he had concurred in the common view that the thyroid gland was functionless in man. When the subsequent development of a cretinoid state in one of his patients was brought to his notice he followed up the 24 of his patients in whom thyroidectomy was thought to have been complete. Six were well, two could not be traced. The other 16 cases had followed a common path. The symptoms, developing four to five months post-operatively, were those now recognized as characteristic of myxoedema. In particular he noted that children so affected were miserable when, after operation, they lost their places in school life and were overtaken in mental development by their younger siblings. The similarity to cretinism was recognized, but identity was not claimed and the term 'cachexia strumipriva' was coined. In the same year Reverdin and Reverdin (1883) described similar results in a series of 20 cases, but remarked that the disorder simulated that described by Gull and by Ord (myxoedema) even more closely than cretinism.

Considerable interest was stimulated by these findings, and by Schiff's (1884) report on the effects of thyroidectomy in animals, and a committee of the Clinical Society of London was appointed to investigate the relationships of sporadic cretinism, myxoedema and cachexia strumipriva. This committee (1888) reported that the last two were identical and that cretinism was myxoedema occurring in childhood. Victor Horsley (1892) reviewed an experimental programme which he had carried out on behalf of this committee. The clinical picture of the experimental disease was still confused by incidental parathyroid removal, but as a result of his studies Horsley put forward the following view of the function of the thyroid gland.

A colloid was secreted by the thyroid gland into its vesicles, and was discharged into the blood stream via the lymphatics. This secretion was essentially connected with the metabolism of blood and tissues, but not specifically with that of the brain. 
The gland was functionally active before birth. In the study of the comparative pathology of thyroidectomy in various species, Horsley found that it had no effect on birds or rodents; in ruminants the syndrome was slow to develop. In man and monkeys the disease was of moderate severity; it was most severe of all in carnivora. The symptoms of the experimental disease, which often took weeks or months to develop, could be precipitated by exposure to cold or by the giving of meat extracts.

The clear association of these symptoms with absence or non-functioning of the thyroid gland cleared the way for attempts at replacement therapy.

Schiff (1884) had shown that in animals the subcutaneous implantation of thyroid tissue could temporarily protect against the effects of thyroidectomy, and Horsley (1890) suggested the application of this method to the treatment of myxoedema in man. This advice was followed by Bettencourt and Serrano (1890) who implanted part of a thyroid gland subcutaneously in a woman of 36 suffering from myxoedema. Improvement started within 24 hours and thereafter she quickly lost all symptoms of the disease; it was properly concluded, from the rapidity of cure, that the effects must have been due to the absorption from the implanted gland of pre-formed secretion, as there had not been time for the graft to vascularize. Murray (1891 and 1892) then tried the subcutaneous injection of a glycerine extract of sheep's thyroid. 'As the secretion normally passed into the blood mixed with the lymph I decided, in testing the efficiency of the extract, to inject it beneath the skin so that it might be absorbed by the lymphatics and so enter the blood as nearly as possible under normal conditions' (Murray, 1900). This remedy was effective, but it was soon shown simultaneously by Mackenzie (1892), and by Fox (1892), that the extract could be given orally with equally good effect. There is an interesting phylogenetic explanation of the efficacy of thyroid by mouth, in that in more primitive species the thyroid gland discharges its secretion directly into the gastrointestinal tract via the thyroglossal duct.

The first recorded case of the use of thyroid gland in the treatment of cretinism is probably that of Byron Bramwell (1894).

In 1896, when substitution therapy in hypothyroidism had been in use for five years, cretinism was discussed at the annual meeting of the British Medical Association (Brit. med. J., 1, 661, 1896). Some of the problems surrounding the management of cretinism had already begun to emerge. The efficacy of substitution therapy was agreed, but perhaps because the first group of cases were long- standing defectives, little reference was made to the mental prognosis, although it is probably from this time that it came to be assumed that if only the case could be diagnosed early enough the mental prognosis would be as good as the physical. At this meeting Rushton Parker noted that there was often no improvement in the legs, due to the 'softening of bones produced by thyroid extract', and Telford Smith observed that the growth of bone was so rapid that softening took place. It was left to John Thomson at the same meeting to identify this complication as the unmasking of latent rickets by rapid bone growth. His comments are worth quoting in full:

'When one sees the bent limbs, the changed epiphyses and sometimes a sort of rickety rosary on the chest wall, along with profuse sweating, nocturnal listlessness, and muscular debility one naturally asks oneself whether, in restoring to these adolescents the growing capacities of babyhood, we have not also given them back the liability to rickets which they had left far behind them. It seems quite probable that this may be so.'

During the last 20 years of the nineteenth century, therefore, the technique of substitution therapy in hypothyroidism became established. During the same period, work in the physiological field established the thyroid gland's requirement of, and affinity for, iodine, and showed that the active secretion of the gland was an iodine-containing globulin (Harington, 1933).

\section{The Effects of Treatment with Special Reference to Mental Development}

An excellent account of myxoedema and cretinism was given by Murray (1900), and it is here, in the final paragraph of his book, that the first authoritative reference is made to the mental prognosis in treated cretins:

The intellectual development is always much slower than the bodily growth and general improvement in all other respects. The shorter the duration of the symptoms has been at the commencement of the treatment the more rapid the improvement in the mental condition, and I think it is only in cases in which the treatment is started early that we can expect normal intellectual development to take place.'

The exact phrasing used by this careful observer and writer should be noted. 'The shorter the duration of symptoms' is not exactly synonymous, as many have since assumed it to be, with 'the earlier in life', for, quite apart from the physical symptoms, a marked mental retardation, present from birth, may of itself bring the child to a physician for diagnosis before the physical signs of disease have become obvious. 
Since the publication of Murray's monograph sporadic cretinism has been generally recognized in this country and thyroid extract by mouth has been the standard treatment. Nearly all writers on the subject have given a good physical and a guarded mental prognosis. There has, however, been a general tendency to make two assumptions, the validity of both of which has been questioned in recent years. The first is that mental development would be normal if the diagnosis were made and treatment instituted as early as possible in every case; and the second, that thyroid dosage should be as high as possible if the best mental development is to be achieved. Aldrich (1936) in particular advised pushing thyroid to the limits of tolerance and was critical of the generally pessimistic attitude to mental prognosis. Tredgold (1929), however, thought that there were probably two types, one in which mental retardation was due to hypothyroidism, and another in which there was 'primary amentia with superadded hypothyroidism'; and Gamper (1928) noted 'a torpor which is myxoedematous and a defect, not accessible to thyroid therapy, which is attributable to arrest of cerebral development and changes in cerebral structure'.

Thomson (1925), from a study of 21 personal cases followed for some years, anticipated in some respects the more fully documented findings of Lewis, Samuel and Galloway (1937a and b) in his description of the personality of the treated cretin: 'As he grows older ... he develops a curious air of apathy $\ldots$ and abnormal deliberation. He knows the few things he does wish to do, and quietly insists on doing them, though he is long about it' ... 'He takes in a great deal more of what is going on than we give him credit for' . . 'His eyes have a steady, patient look, very different from the shifting vacant expression seen in most imbeciles.' Thomson noted that in a considerable proportion of cases the child remained an imbecile, and that under these circumstances the power of speech was almost or quite in abeyance.

In the past 20 years several papers have been published reviewing the prognosis for treated cretins. This circumstantial testimony all leads one to believe that the basic intelligence, and perhaps certain personality defects, are fixed by the time of birth, and that all that thyroid replacement can do is to relieve the physical symptoms, and, drawing aside like a veil the 'myxoedematous torpor', reveal the individual behind, who may be normal, but who in the great majority of cases will show defects both of intelligence and of personality. But there is as yet no study of a large series of cretins diagnosed and adequately treated from the age of 3 months, which alone can authoritatively settle the question of the effect of early treatment on mental prognosis.

Lewis et al. (1937a and b) made a retrospective survey of 79 cases collected from a variety of institutions and hospitals in London, all of which had been under treatment for some years. An attempt was made to assess the value of substitution therapy in the treatment of the mental retardation. The previously reported observation that slowness of the mental process was the distinguishing characteristic of the treated cretin was confirmed; it was added that these children were placid in a congenial environment but pig-headed, bad-tempered, and obstinate if crossed. Only four out of 79 were markedly depressive. A feature recorded here as a new observation, but foreshadowed in Thomson's description in 1925, is that of obsessional behaviour; many of the individuals were tidy, clean, and repetitive to an abnormal degree, and painstakingly thorough in anything they undertook. Only one in five had an I.Q. over 80 , but it should be noted that this was a retrospective study and that the sources of many of the cases were mental institutions. There was no excessive scatter in the behaviour in different fields of activity, although consistently lower scores were obtained in tests in which speed was taken into account. Data on the early histories were inadequate, but it was concluded that in general the earlier the clinical onset of symptoms the worse the mental prognosis. No strict relationships could be found between the final intellectual level and either the age at which treatment had been started on the one hand or the probable adequacy with which it had been maintained on the other. Two of the more striking exceptions to these generally assumed relationships are quoted: one, a child who, following treatment from the age of 4 months, achieved a final I.Q. of 34 only, and another who was not treated until the age of 11 , but whose final I.Q. was 101.

Kerley (1940) reported two cases which appeared to uphold the optimistic views of Aldrich (1936). Both were typical cretins who, following treatment from the age of 7 months and 10 weeks respectively, with thyroid grains 3 daily, were 'honours students' at the ages of 9 and 16 years. The author knew of six others who had been treated since infancy and who at ages between 16 and 40 years had 'normal mental endowment'. Without knowing the size of the series of cases from which these examples are drawn, however, no deduction as to the frequency of such happy results can be made.

McDonald, Brown and Bronstein (1940) described the background and social adjustment of 27 children who had been under treatment for seven years. 
A wide range of intelligence was found, from defective to average, the majority being high-grade defectives. Most had been able to establish habits in accordance with those of normal children of the same mental age. The authors concluded that glandular therapy did not overcome low intelligence or unwholesome parental attitudes.

Goodkind and Higgins (1941) studied 23 children who had been under sustained treatment for from five and a half to 24 years. All except one of the cases had shown evidence of the disease in the first year of life and were therefore presumably congenital cretins. In all cases the diagnosis was confirmed by interruption of treatment. Six had I.Q.s of 90 to 112, six of 70 to 89, and 10 of below 70 (one of 20, one of 15). The ages at diagnosis and beginning of treatment were usually much earlier in the ultimately mentally retarded cases than in those of normal intelligence. Evidence is given that thyroid grains $1 \frac{1}{2}$ daily will raise to normal the basal metabolism of the athyreotic patient over the age of 6 years. The degree of thyroid deficiency, as measured by the amount of thyroid necessary to maintain normal metabolism, was not proportional to the degree of mental retardation. It was concluded that the cerebral deficiency could probably be regarded as congenital and from the same cause as the thyroid damage. The value of serum cholesterol estimations was studied and it was found that the cholesterol level correlated closely with the B.M.R. When treatment was interrupted to confirm the diagnosis the serum cholesterol level rose significantly within one month in $75 \%$ of cases, and within two months in all.

Bruch and McCune (1944) made a psychiatric study of 23 cases selected for adequacy of records, and of physical response to treatment. The diagnosis was confirmed in each case by interruption of treatment. Intellectual development is described as proceeding under treatment without increase in I.Q. in all cases but one. The importance of this observation is, however, diminished, as the authors concede, by the fact that the first psychometric examination was carried out many months, and sometimes years, after treatment had started. Neither the age at the beginning of treatment nor the regularity thereof are considered to correlate with mental prognosis, but it is noted that if treatment is delayed beyond the age of 3 years full stature may not be achieved. Valuable comments are made upon three individual cases. The best child, who achieved a final I.Q. of 112, had been treated from the age of 5 months, but had been noted to be 'bright' before treatment, although of typically cretinoid appearance. The story of a second case suggests strongly that over-dosage with thyroid, apart from failing to improve the intelligence, may lead to neurotic disturbances and thus interfere with the best use of limited mental equipment. A third child was observed to perform skilled acts better with no thyroid at all than on a previously excessive dose. It was concluded that mental development showed considerable independence of treatment, and that functional development before treatment began was the best index of capacity for future progress: that the optimal dosage of thyroid must be found by experiment in each case, bearing in mind that thyroid in excess of the requirements for physical response has a 'disrupting influence on the personality and on integration'; and that by the time of birth the 'potentiality for mental development has become independent of the activity of the thyroid gland'.

Radwin, Michelson, Berman and Kramer (1949) made a similarly careful clinical and psychometric study of 12 adequately proved cases, which had been observed for from 13 to 23 years, usually since infancy, and who were currently aged $13-26$ years. An average dose of 2 to 3 grains a day had been given throughout the period. Seven cases had I.Q.S of 82 to 103, two of 77 . These nine cases had all made satisfactory social adjustments and were useful members of society. The I.Q.s of the other three were 42, 57, and 67 respectively. Physical development had been normal in all cases. Although most of the rise in I.Q. occurred in the first three years, significant rises were observed after this period had elapsed in two-thirds of the cases. Behaviour characteristics are described which are mildly abnormal and which are present irrespective of the level of intelligence. The speech is hesitant and slurring, movements and gait are slow; some are euphoric and emotionally labile. They are better at manual than at intellectual work. 'Their mannerisms, attitudes and emotional characteristics were not those of fully normal adolescents or adults.'

\section{Cretinism at The Hospital for Sick Children, Great Ormond Street, 1917-1938}

An attempt was recently made to follow up a series of cretins treated at The Hospital for Sick Children between 1917 and 1938. No out-patient records are available for this period, during which only 36 cases were admitted. Seven of these children died while in hospital. Of the other 29, only five could be traced. One of these had died shortly after discharge. The other four were re-examined in 1953. Although this material is quite inadequate for the study of the series as a 
whole, it so happens that these four cases illustrate well some of the vagaries of the disease.

\section{Case Reports}

Case 1. I.G., a girl (No. 219102), first walked at the age of 2 years and 3 months and had just begun to talk at the age of 3 when it first occurred to her mother that she was 'backward'. The diagnosis was made, and treatment was started at the age of 4 when she had whooping cough. Treatment changed her whole appearance and behaviour for the better; she learned to talk properly in a few months, and gained six inches in height in the first year. She was admitted to Dr. Poynton's ward in 1924 at the age of 9 years and 3 months (weight 41 lb., height $40 \frac{1}{2}$ in.). There was no evidence of cretinism at this time. She was later looked after by Dr. Tredgold at University College Hospital, who increased the thyroid to 8 grains a day but had to reduce it again as the pulse rate went too high. She was educated at a special school and was always backward.

She had always lived with her mother, who attended with her in 1953, and who said that she was normally behaved at home, but could take no responsibility and needed 'constant probing'. Her vocabulary, conversational responses, and appearance were normal. Menstruation had begun at the age of 15 and had always been normal and regular. The epiphyses were normally fused. Her I.Q. is 96 .

In this case there is good evidence that treatment with thyroid has been adequate. Her formal intelligence is within the normal range, and her social inadequacy must be attributed to a defect of personality rather than of intelligence.

Case 2 C.M., a girl (No. 219105), was brought to hospital by her mother on account of failure to sit up; she was diagnosed by Dr. Cockayne at the age of 1 year and 1 month and treatment was started. It was apparently not adequately maintained, for on admission to Dr. Poynton's ward in 1927 with pyrexia of unknown origin at the age of 21 years, she was stunted and fat, the skin was dry, the anterior fontanelle was open and only four teeth had erupted.

She attended with her mother in 1953. She had not begun to talk until the age of $3 \frac{1}{2}$ years. She can neither read nor write, but plays the piano excellently by ear. She is helpful about the house but would not be capable of independent life. She is very methodical, never leaves anything out of place, and is meticulous about her personal appearance. Menstruation began at the normal time and has always been regular. The epiphyses have fused normally. Her I.Q. is 39.

This child, who is severely defective, shows well the obsessional behaviour described by Lewis, and also illustrates the dissociability of intelligence and musical ability.

Case 3. A.S., a boy (No. 211916), was always backward. He sat up at 4 years and began to walk stiffly at the age of 5 years. He was treated intermittently from the age of 6 years, but when admitted to Dr. Paterson's ward in 1935 at the age of 10 was a 'typical cretin'. Treatment with thyroid was started then and has been continuous since.

He attended with his parents in 1953. Although showing no cretinoid features, he is obviously defective. He understands the spoken word but is totally dumb. He has a fairly well developed sign language. His hands, but not his arms, are in continuous repetitive movement, and he wears an anxious expression. There is a mild spastic quadriplegia.

He is markedly obsessional. He takes his clothes off tidily, folding them up neatly one by one and will wander round the house picking up little bits of thread and paper and putting them into a wastepaper basket. The epiphyses are normally fused. His I.Q. is 25.

This boy, the most defective of the four, shows the most marked obsessional behaviour and 'the power of speech', as Thomson (1925) noted in some of his cases, 'is in abeyance'.

Case 4. I.D., a boy (No. 219114), was noticed to be backward at the age of 6 months and was treated intermittently with thyroid until the age of 3 or 4 , since when treatment has been continuous and adequate. He was admitted to Dr. Thursfield's ward in 1935 at the age of $1 \frac{1}{2}$ years when he had a typically cretinoid appearance, and ossification was delayed: he lost weight rapidly on treatment with thyroid; for most of the third year of life he was in hospital with 'tuberculosis of the spine', and wedging of the second lumbar vertebra was radiologically visible in 1953.

He went to normal schools and was top of his class in English. He left school at the age of 15 and his apprenticeship to an upholsterer ceased following a difference of opinion with his master. He was at this time quicktempered and unsociable. 'I would stay at home and read a book rather than go anywhere. I crept into my shell and this had an adverse effect upon me.' He managed to overcome this tendency after treatment by a psychiatrist. He is now a trainee engineer. It was not possible to arrange a formal test but his intelligence is clearly within the normal range. His conversation and attitude to life are introspective, detailed, repetitive, and obsessional.

Although symptoms were clearly present from an early age, and treatment was inadequate at least until the age of $1 \frac{1}{2}$ years and probably until the age of 3 or 4 years, his mental development is normal. He shows characteristic obsessional traits.

It has long been recognized that so far as the physical symptoms of the disease are concerned thyroid by mouth is a completely effective substitution therapy. The initial dosage should not be in excess of $1 / 6$ grain a day and this should be increased only gradually over weeks or months to the optimal dosage which probably never exceeds 2 grains a day. Study of the records of the seven children who died at Great Ormond Street between 
1917 and 1938 confirms the impression recorded by Pugh (1952), and well documented in the literature that the greatest hazard to the life of the young cretin is an unnecessarily high starting dosage of thyroid or its over-rapid increase. Death was probably attributable to this cause in all seven cases. The effect of treatment upon mental development is less consistent, and the majority of adequately treated cases remain on the borderline of educability. A number are more grossly defective, and only a small minority achieve normal intelligence. The hypothesis that the mental prognosis would be greatly improved if all cases were treated from the earliest possible time at which a clinical diagnosis could be made has never been critically tested, and there is much to suggest that this would not be the case.

\section{Types of Sporadic Cretinism}

Until the last few years there had been no prospect of making any progress in splitting sporadic cretinism up into its constituent entities, although it has been clear for many years that it was not a single disease.

Complete agenesis of the thyroid gland was first demonstrated by Curling (1850) and in all the published series this has been the commonest finding. But in roughly $10 \%$ of necropsies the gland has been present, and usually enlarged, and the clinical presence of a goitre in a minority of cases has also been remarked. Murray (1900) quotes two series. Fletcher Beach found goitres clinically in seven out of 116 cases, and of 16 of this series which came to necropsy two had large thyroid glands. Byron Bramwell found a thyroid gland in one out of 10 necropsies. Osler (1905) found goitres clinically in seven out of 60 cases.

In the period 1917-1938, seven patients died in The Hospital for Sick Children. Of the six cases which came to necropsy, the thyroid gland was entirely absent in five, and was enlarged in one case.

Pugh (1952) recently analysed the available records of the 21 necropsies done on cases of cretinism in the same hospital between 1860 and mid-1952. The thyroid gland had been reported as 'entirely absent' in 14 cases. Of the remaining seven, it had been 'small' in two, 'normal' in one, and 'enlarged' in four.

The recorded familial incidence is also such as to suggest two distinct diseases, for the familial cases seem to be concentrated in a very small percentage of the families. Murray (1900) refers to two such families: in one of these, four out of 11 members were affected, and in the other, three members were affected.
Until recently these two criteria, upon each of which cretinism could be split into two separate entities, appeared to be unrelated. Stanbury and Hedge (1950) reported a family in which four of seven children were goitrous cretins, and more recently McGirr and Hutchison (1953) have reported radio-iodine studies upon 12 cases of non-endemic goitrous cretinism. Of these 12 cases, four were in one family and two others were closely related. The defect appeared to be one affecting the capacity of the thyroid gland to synthesize thyroxine. Radio-iodine was taken up rapidly, in such a way as to suggest hyperfunction in the gland, and was subsequently found in the blood stream in a proteinbound form, but this could not have been thyroxine as the cases responded normally to thyroid extract given by mouth. Similar results were obtained from radio-iodine studies in Stanbury and Hedge's cases.

These findings appear to link the familial and goitrous cases and to suggest the possibility that there is a form of cretinism due to an enzyme defect of the thyroid gland controlled perhaps by a new mutant dominant gene. Whatever may come of further investigation of this group of cases, the study of radio-iodine uptake by the gland, and of its subsequent distribution and excretion in relation to the clinical findings and response to administered thyroxine opens up new possibilities for the precise definition of all thyroid disorders, including the sub-division of cretinism, and will form an integral part of any future researches in this field.

\section{The Cause of Mental Defects in Athyrea}

The failure of thyroid treatment to cure mental retardation was for long held to be due to delay in diagnosis and treatment; this view has come to be largely abandoned on evidence which, though good and abundant, is still circumstantial. For although non-endemic cretinism has been recognized in this country for 80 years, there has been a consistent failure to observe groups of cases in such a way that the problems of management and prognosis could be solved.

The association of mental defect with cretinism can be explained in two ways. Either they are due to separate lesions of common cause-and analogous therefore to component parts of the rubella syndrome -or the mental defect is the result of thyroxine starvation of a potentially normal brain. The idea that mental defect and cretinism might be two separate congenital disorders, of common origin but not causally related to each other, seems to have arisen (Tredgold, 1929) as an attempt to explain the failure of thyroid substitution therapy to achieve 
all that was expected of it. No good evidence in favour of this aetiology has been obtained, however, and it seems likely that evidence against it will accrue in the process of classifying the diseases hitherto described together as cretinism. If cretinism and defective development of the brain were unrelated except through common origin it is unlikely that they would co-exist in cases of cretinism due to different pathological causes. If therefore it is shown with the help of radio-tracer studies that mental defect is associated with non-endemic cretinism due to causes other than simple athyrea, it will be highly probable that the cretinism is the cause of the mental defect rather than of common origin with it. Studies of endemic cretinism may also provide evidence on this point. Endemic cretinism is said to be associated with a mental defect more consistent and more severe than that of sporadic cretinism. It is to be hoped therefore that precise studies of the mental prognosis in a series of treated endemic cretins will be made before simple public health measures have eradicated the disease throughout the world.

It seems inherently more probable, and it is a more economical hypothesis, that the mental defect follows thyroxine starvation of the rapidly developing brain ante-natally and in the early months of separate existence.

But even if it could be proved that thyroxine deficiency was the cause of the mental defect it would by no means follow that cases could be diagnosed early enough to remedy the defect in mental development. Knowledge of the age at which foetal thyroid secretion begins, the age at which, if at all, it becomes necessary to ante-natal development, and of the capacity of maternal thyroxine to cross the placental barrier and replace it when deficient, is very limited. The following details are taken from Clement Smith (1945):

The thyroid is structurally complete at the third to fourth month and colloid is stored at six months. Thyroxine has been identified in the human foetus at the third month and iodine is concentrated in the thyroid gland by the end of the first third of development. There is evidence that the placenta can transmit thyroxine in both directions, but the consistency of this interchange and its quantitative adequacy are not known. It is probably not an unimpeded flow. In the first few days of post-natal life the colloid is depleted and the gland becomes hyperaemic.

Before sure knowledge can be obtained of the exact relationship between cretinism and its facultatively associated mental defect more will have to be learned about the thyroxine requirements of the individual in the few weeks before and after birth.
In cases of congenital athyrea, which form the great majority of cretins, there can be no autochthonous thyroxine in the individual at any time: if, therefore, thyroxine is necessary to brain development at any phase it must in some cases be obtained from another source, for a minority of individuals so afflicted are of normal intelligence. The variability of mental development from case to case could only be accounted for by variations in the adequacy of such alternative supply. The only conceivable alternative sources are placentally transmitted maternal thyroxine ante-natally, and transmission via the milk supply post-natally. The greater severity and consistency of mental defect in endemic cretinism might on this hypothesis be accounted for by the fact that in these cases the maternal thyroid is itself working under difficulties while competing with the foetus for the limited supply of iodine.

This hypothesis assumes a direct dependence of the foetal brain upon thyroxine for certain phases of its development. There is, however, another highly speculative alternative which seems worthy of consideration. An inadequate level of circulating thyroxine stimulates the production of thyrotrophic hormone, whether a thyroid gland is present or not. In cases of cretinism, the hypophysis is hypertrophied (Horsley, 1892). Could it be that this hypertrophy of a single function in early foetal life takes place at the expense of other, and as yet unknown pituitary mechanisms controlling cerebral development?

\section{Conchusions}

Sporadic cretinism was recognized in this country towards the end of the nineteenth century, and it was soon shown that thyroid substitution therapy was effective in the control of the physical symptoms of the disease and in securing normal physical development.

The position with regard to mental prognosis is, however, still confused and the field is open for long-term studies upon the effect of the earliest possible diagnosis and treatment.

It has been a consistent finding so far that the ultimate intelligence of adequately treated children varies widely and that the degree of success in this respect shows no positive correlation either with early diagnosis or with the degree of persistence with which treatment has been maintained. There is, on the other hand, some evidence that the mental prognosis is worse in those cases which are diagnosed and treated from the earliest months of infancy. It should be noted that there is one source of confusion in analysing evidence of this kind which is common of the study of a variety of congenital 
diseases in which clinical severity varies from case to case. This is that the more severe are likely to be diagnosed earlier in life than milder cases, thus unjustifiably weighting the statistical evidence against the value of early treatment.

It is possible that cases in which mental defect is established by, or shortly after birth, will tend to be diagnosed earlier in life and while the physical symptoms are minimal, merely because the mental retardation itself has brought the child to the notice of the physician.

It is clear that sporadic cretinism is not a single disease. That it consists in not less than two entities is proved by the observation at necropsy that the thyroid gland is present in some cases but not in others. It may be possible to define the pathology of cases in which a gland is present by means of radio-iodine studies.

Under treatment the majority of cases reach the borderline of educability; many are more grossly defective and only a minority achieve normal intelligence. In addition to the mental defect there are often personality defects which may interfere with the social performance of those who, in terms of formal intelligence, are on the borderline of educability.

Initial doses of thyroid should not be more than $1 / 6$ grain daily as most of the mortality appears to be due to an excessive starting dosage, and the optimal dosage, which should seldom exceed 2 grains a day, need not be reached for weeks or months. There is a general agreement that increases in dosage over 2 to 3 grains a day are valueless. It has been shown that $1 \frac{1}{2}$ grains of thyroid will replace the normal activity of the thyroid gland in a child of $6,1 \frac{1}{2}$ to 2 grains would, therefore, probably never be too little, and could hardly be too much in the presence of thyroid deficiency because even if there was some residual function in the thyroid gland this would presumably be controlled by normal physiological mechanisms to achieve a satisfactory total level of circulating thyroxine.

There is, on the other hand, good evidence that excessive dosage may interfere with development of the personality and with the most efficient use of what mental equipment is available. If, as is here suggested, the basic intelligence is fixed by the time the case is diagnosed, and perhaps by the time of birth, then no great improvement can be expected from earlier diagnosis, and the prognosis as regards mental development will remain as is recorded in the literature; that is to say, the majority will be in the I.Q. range 70-95, some will be grossly defective, and a very few will be of normal intelligence. This point can only be further clarified by a closer and longer study of a series of earlier treated cases than the literature yet contains.

\section{Summary}

It is certain that there is more than one type of non-endemic cretinism, for in a minority of cases the thyroid gland is apparently normal or enlarged. Recent studies suggest that sporadic cretinism without athyrea may be a familial disease. Radiotracer techniques for the study of iodine metabolism offer the hope of further definitions of the two or more diseases which comprise non-endemic cretinism.

The work upon which this paper is based was carried out while holding a research fellowship at The Hospital for Sick Children, and I wish to express my thanks to the Research Committee of the hospital for the opportunity afforded.

\section{RefERENCES}

Aldrich, C. A. (1936). J. Pediat., 8, 381.

Bettencourt, R. and Serrano, J. A. (1890). Sem. méd., Paris, 10, 294. Bramwell, B. (1894). Brit. med. J., 1, 6.

Bruch, H, and McCune, D. J. (1944). Amer. J. Dis. Child., 67, 205.

Bruch, H. and McCune, D. J. (1944). Amer. J. Dis. Child,

Curling, T. B. (1850). Med.-chir. Trage, C. H. (1871). Ibid., 54, 155.

Fox, E. L. (1892). Brit. med. J., 2, 941.

Gamper, E. (1928). In Bumke, O. Handbuch der Geisteskrankheiten, vol. 10. Berlin.

Goodkind, R. P. and Higgins, H. L. (1941). New Engl. J. Med., 224, 722 .

Gull, W. W. (1874). Trans. clin. Soc., Lond., 7, 180.

Harington, C. R. (1933). The Thyroid Gland. London.

Horsley, V. (1890). Brit. med. J., 1, 287.

(1892). Ibid., 1, 215, 265.

Kerley, C. G. (1940). Arch. Pediat., 57, 432

Kocher, T. (1883). Arch. klin. Chir., 29, 254.

Lewis, A., Samuel, N. and Galloway, J. (1937a). Lancet, 1, 1505. Lewis, A., Samuel, N. and Galloway, J.

McDonald, J. W., Brown, A. W. and Bronstein, I. P. (1940). Amer. J. Dis. Child., 59, 1227.

McGirr, E. M. and Hutchison, J. H. (1953). Lancet, 1, 1117.

Mackenzie, H. G. W. (1892). Brit. med. J., 2, 940.

Murray, G. R. (1891). Ibid., 2, 796.

(1892). Ibid, 2, 449 .

- (1900). Diseases of the Thyroid Gland, Part I, Myxoedema and (1900). Diseases of the
Cretinism. London.

Ord. W. M. (1878). Med.-chir. Trans., Land., 61, 57.

Osler, $\mathbf{W}$. (1905). The Principles and Practice of Medicine, 6th ed. London.

Parker, W. R., Thomson, J. and others (1896). Brit. med. J., 1, 661

Pugh, R. C. B. (1952). Personal communication.

Report of Myxoedema Committee (1888). Trans. clin. Soc., Lond.

Radwin, L. S., Michelson, J. P., Berman, A. B. and Kramer, B. (1949). Amer. J. Dis. Child., 78, 821.

Reverdin, J. L. and Reverdin, A. (1883). Rev. méd. Suisse rom., 3, $169,233,309$

Schiff, M. (1884). Ibid., 4, 65, 425.

Smith C A (1945). The Physiology of the Newborn Infant. Spring field, Ill.

Stanbury, J. B. and Hedge, A. N. (1950). J. clin. Endocr., 10, 1471

Stanbury, J. B. and Hedge, A. N. (1950). J. clin. Endocr., 10, 1471. Children, 4th ed., pp. 440-61. Edinburgh.

Tredgold, A. F. (1929). Mental Deficiency (Amentia), 5th ed. p. 274. London.

Wilkins, L. (1938). J. Pediat., 12, 429. 